\title{
TIBBI MALPRAKTIS
}

\author{
MEDICAL MALPRACTICE
}

\author{
L. Verda Ersoy \\ Türk Tabipleri Birliği Hukuk Bürosu, Ankara, Türkiye \\ e-mail: verdasagun@gmail.com \\ DOI:10.5152/tcb.2014.004
}

\section{Özet}

Tıbbi malpraktis nedeniyle sorumluluk bir kusur sorumluluğudur. Ancak bu kusur, sadece hekime mal edilemez. Tıbbi yanlış uygulamaların temelini, önemli ölçüde "sistem" teşkil eder. Hekim hatası olarak değerlendirilen olgularda, kusurlu eylemin altında yatan nedenlerin saptanması ve hekimleri hataya sevk eden bu nedenlerin giderilmesi, sorunun çözümü için zorunludur. Bugün uygulanan sağlık politikaları ve sunulan çözüm önerileri, tıbbi malpraktis olgularını önlemeye yönelik değildir. Mevcut sistemde, kimi zaman gerçek durum perdelenmekte, hemen her durumda hekimler sorunun odağı gibi gösterilmektedir. Hekimlerin hastaları ile karşı karşıya getirildiği, kendilerine ait kusurun idareler tarafından sahiplenilerek eksikliklerin giderilmesine yönelik adımların atılmadığı ve konunun bütünlüklü olarak ele alınmadığı, bir durumda, bu sorunun gerçek bir çözüme kavuşturulması olanaklı değildir.

Anahtar kelimeler: Malpraktis, tıbbi hata, hekimin hukuksal sorumluluğu

\section{GiRiş}

Çok daha geniş bir anlamı ifade etmesine karşın bugün "tıp hukuku" denildiğinde, akla yaygın olarak "tıbbi malpraktis" ya da diğer bir isimlendirmeyle "tıbbi kötü uygulama" kavramı gelmektedir.

Özellikle tıp uygulamalarından kaynaklanan sorunlar kamuoyunun gündelik tartışmalarına girmekte, daha çok sansasyonel yönleriyle yazılı ve görsel basın tarafından sürekli gündemde tutulmaktadır. Ancak genelde toplum ve hatta hekim kamuoyu bile, özünde ne olup bittiğinden yeterince haberdar değildir.

Artık, klinik ve sosyal sonuçlar doğuran tıbbi malpraktis meselesinin, hekimlerin aldıkları cezalar ve ödedikleri tazminat tutarları gibi ilgi çekici sonuçları bir yana bırakılarak, etik ve hukuksal boyutları ile çok yönlü ele alınması gerekmektedir.

\section{Abstract}

Liability grounded on medical malpractice is a defect liability. However, It is not possible to impute all defect to the medical doctor since the fundamental reason behind medical malpractices is the system itself.

In the cases considered as doctors' fault, It is crucial to determine the facts beneath the defective practice and the problems that lead doctors malpractice must be ceased. Current medical policies and submitted solutions are far from being preventative for medical malpractice cases. The existing system actually conceals the real situation by indicating doctors as the focal point of liability.

Unless the relevant authorities are willing to take responsibility and compensate the deficiencies that the system cause, the controversy between the patients and doctors would remain, and complication would never truly be solved.

Key words: Malpractice, medical error, legal responsibilities of doctors

\section{HEKIMIN HUKUKSAL SORUMLULUĞU}

Tıbbi Deontoloji Tüzüğü’nün1 2. maddesinde; “Tabip ve diş tabibinin başta gelen vazifesi, insan sağlığına, hayatına ve şahsiyetine ihtimam ve hürmet göstermektir." denilmekte, bu bir satırda adeta evrensel hekimlik değerlerinin özeti yapılmaktadır. Her tıbbi malpraktis olgusunda, bu ilkenin ihlal edildiğinin kabulü gerekir.

Ancak tıbbi malpraktis, çoğu zaman hekimin salt kişisel kusurundan kaynaklı değildir. Bununla birlikte sağlık hizmeti, hekim merkezli bir sistem içinde verildiğinden tıbbi malpraktis olgularında hekim, hukuksal sürecin baş aktörü olmaktadır. İstenmeyen kötü sonuçların ortaya çıktığı hemen her durumda, hasta ve hasta yakınları tarafından gerçekte ortada bir kusurun var olup olmadığı ve varsa bu kusurun kimden kaynaklandığı dahi araştııımaksızın "hekim hatası" dillendirilmektedir. 
Gelişen teknoloji ile birlikte kişilerin sağlık hizmeti sunucularından beklentisinin artması, bilgiye erişimin kolaylaşması, kişilerde bir algı ya da bilinç yaratılması, ayrıca hekimlerin bilgisi, becerisi ve hastaya yaklaşımını sorgulayan olumsuz tutumu nedeniyle haklı eleştiriler alan medyanın da etkisi ile hekimler aleyhine yapılan hukuksal başvuru sayısı gün geçtikçe artmaktadır.

Tıbbi malpraktis iddiasının ortaya atıldığı durumlarda hekimler, bir anda çeşitli hukuksal süreçlerle karşı karşıya gelebilmektedirler. Bunlar;

1. Ceza davası

2. Hukuk (tazminat) davası

3. İdari soruşturmalar

4. Meslek kuruluşu tarafından yürütülen disiplin işlemleridir.

Maddi olayların özdeş olduğu hallerde dahi nitelendirme, hukuki dayanakları, kapsamı ve korumayı gözettiği değerler açısından farklı özellikler taşıyan bu süreçlerden birinin işletilmesi, diğerlerinin yapılmasına engel olmamaktadır. Dolayısıyla hekim, bu süreçlerden birisi ya da birkaçı ile aynı anda baş etmek zorunda kalabilmektedir.

Adli hukuksal süreçlerde, hekimin sorumlu tutulabilmesi için; eyleminin hukuka aykırı olması, kusurlu bir davranışının bulunması, hastada bir zarar ortaya çıkması ve hekimin eylemi ile hastada meydana gelen zarar arasında illiyet bağı (nedensellik/sebep-sonuç ilişkisi) kurulabilmesi gerekir².

Ancak idari soruşturmalar ile meslek kuruluşu tarafından yürütülen disiplin işlemlerinde, hekimin cezalandırıması için her zaman bir zararın doğması aranmaz; ortada hukuka aykırı bir eylem ve kusurlu bir davranışın var olması yeterlidir. Zira ister idari, isterse mesleki olsun, disiplin işlemlerinin amacı benzerdir. Disiplin işlemleri; idari iç düzen gerekleri, kamu hizmetinin iyi işlemesini sağlama gibi gerekçelerle kurum düzenini ve bu yolla kamu yararını sağlamak, kişilere görevlerini yerine getirirken daha dikkatli olmaları gerektiğini öğretmek, kişileri suç işlemekten caydırmak ve o görevi yürütmemesi gerektiği anlaşılanları görevden uzaklaştırmak amacıyla yapılmaktadır. Hekimlerin meslek kuruluşu olan Türk Tabipleri Birliği ${ }^{3}$, aynı zamanda mesleğin kurallarını hatırlatmak ve evrensel mesleki değerleri ve deontolojiyi korumak amacıyla disiplin cezaları vermektedir.

Hekimin bu hukuksal süreçlerde sorumluluktan kurtulabilmesi için öncelikle, "tıbbi el atma" olarak tanımlanabilecek eyleminin hukuka uygun kabul edilebilmesi gereklidir. Hukuka uygunluktan ise, ancak hekimin o işlemi yapmaya yetkili olması, hastanın aydınlatılmış onamını alması ve mesleğin gereklerine uygun davranması durumunda söz edilebilir.
Bilindiği gibi hekimin, ancak eğitimini aldığı ve ehliyetli olduğu tıbbi müdahaleleri yapması olanaklıdır. Acil durumlar dışında uzmanlık gerektiren konularda tıbbi müdahale yapılabilmesi, o alanda uzman olmayı gerektirir.

Ayrıca hastanın; sağlık durumu ve konulan tanı, tedavi seçenekleri ve riskleri, önerilen tedavi yönteminin türü, başarı şansı ve süresi, tedavi yönteminin hastanın sağlığı için taşıdığı riskler, verilen ilaçların kullanıIışı ve olası yan etkileri, hastanın önerilen tedaviyi kabul etmemesi durumunda hastalığın yaratacağı sonuçlar konularında, aydınlatılan kişinin kültürel, toplumsal ve ruhsal durumuna özen gösteren bir uygunlukta ve anlayabileceği biçimde bilgilendirilmesi gerekir. Böyle bir bilgilendirme yapıldıktan sonra hastanın ve gerekli durumlarda yakınlarının rızası alınmalı ve belgeye bağlanmalıdır.

$\mathrm{Bu}$ gereklilikleri yerine getirmeyen bir hekimde olduğu gibi, hasta kayıtlarını gerektiği şekilde tutmayan, hastasına karşı sır saklama, sadakat ve özen yükümlülüğünü yerine getirmeyen, tanı koyma ve tedavi konusunda uygun bilimsel metodu seçip uygulamayan bir hekimin de mesleğinin gereklerine uygun davrandığından söz edilemez.

Dünya Tabipleri Birliği tıbbi malpraktisi, tedavi uygulaması bakımından mesleğin gereği üzerinden tarif etmekte ve "hekimin tedavi sırasında standart güncel uygulamayı yapmaması, beceri eksikliği veya hastaya tedavi vermemesi ile oluşan zarar" olarak tanımlamaktadır. Burada belirtilen "standart güncel uygulama", "aynı durumda ve aynı şartlar altında makul (orta seviyede) bir hekimin, güncel bilimsel kurallara uygun şekilde, gerekeni yapması" olarak ifade edilebilir.

Bu tanımlardan yola çıkarsak, her tıbbi işlemde bir "olması gereken" ve bir de "olan" vardır. İşte bu iki durum arasında bir fark doğduğunda, konunun tıbbi malpraktis yönünden değerlendirilmesi gündeme gelmektedir.

Yargıya intikal eden böylesi olaylarda, olanla olması gereken arasındaki farkı ve bu farkın nedenlerini saptayan ve süreçte belirleyici olanlar, bu alanda teknik bilgi ve beceriye sahip olan hekim bilirkişilerdir. Hukukçuların rolü ise gerçeğin ortaya çıkarılması için gidilecek rotanın çizilmesi ve hukuki yorumun ortaya konulması ile sınırlı kalmaktadır. Bu bakımdan yargılamayı yapacak mercilerce bilirkişinin seçimi, gerçekten büyük bir önem taşımaktadır. Tıbbi hata iddiasının araştırımasında, sıklıkla karşılaştığımız şekilde Adli Tıp Kurumu ve Yüksek Sağlık Şurası'na başvurulabileceği gibi, üniversite tıp fakültelerinin ilgili anabilim dallarından veya o alanda uzman herhangi bir hekimden bilirkişi görüşü istenmesi de mümkündür. 
Önlerine gelen dosyalarda bilirkişilere düşen, ortada kusurlu bir eylem olup olmadığını irdelemektir. Bugün Yargıtay, hekimlerin en hafif kusurlarından bile sorumlu olduklarını benimsemiștir. Hekimin kusuru; hatalı bir uygulama yapması şeklinde olabileceği gibi, yapması gereken bir şeyi yapmaması şeklinde de gerçekleşebilir. Hekimin sorumlu tutulabilmesi için ancak ve ancak kusurlu bir eyleminin saptanması gerekir.

Hekim, bilimsel kurallara uygun olarak gerekli tanıyı koymuş ve tedaviyi olması gerektiği gibi uygulamış ise, artık ortaya olumsuz bir sonuç çıksa bile sorumlu tutulamaz. Zira tıbbi işlemler, sonucu garanti edilebilir olmayan işlemlerdir ve "izin verilen bir risk" alanı içinde yapılmaktadır. Hekim her türlü özeni gösterdiği ve alabileceği her türlü önlemi aldığı halde dahi kötü sonuçlarla karşılaşmak, tıbbi uygulamalarda her zaman olasılık dâhilindedir. Hasta bu konuda önceden bilgilendirilmiş olmak kaydı ile hekim, "komplikasyon" olarak adlandırılabilecek olan bu tür durumlardan sorumlu tutulamaz. Ancak hastada ortaya çıkan komplikasyonların zamanında fark edilmemesinin ve komplikasyon yönetiminin tıp kurallarına uygun şekilde yapılmamasının, tıbbi malpraktis olacağı akılda tutulmalıdır.

\section{KUSURLU EYLEME YOL AÇAN NEDENLER}

Tıbbi malpraktis, salt hekimin kişisel kusurundan kaynaklı değildir. Kötü sonuçların ortaya çıkmasına giden yolda, çoğu zaman başka faktörler etkilidir. Kusurlu eylemler;

- Gerekli sayıda ve nitelikte ekip üyesinin bulunmamasına,

- Sağlık finansmanındaki yetersizlik nedeniyle ekipman, araç-gereç ve mekan yetersizliğine,

- Kışkırtılan talep ya da gereken zaman ayrılamayan hastaların tekrar başvuruları ile de artan hasta yükü,

- Sağlık personelinin olumsuz çalışma koşullarına

- Cihazların bozuk olması ya da kalibrasyonun yapılmaması gibi teknik eksikliklere,

- Olguyu konsülte edememe gibi işbirliği yetersizliğine,

- Diğer sağlık personelinin beceri eksikliğine ve hatalı uygulamalar yapmasına,

- Yönetsel sorunlara,

bağlı olarak ortaya çıkabilmektedir. Tıbbi hata olgularında kusur incelemesi yapılırken bu ve benzeri idari kusurların belirlenmesi gerçekten son derece önemlidir.

Bütün bu olumsuzlukların yanı sıra, "hasta yararı" yerine "hasta memnuniyeti" kavramı koyularak sağlık sisteminin biçimlendirilmesi ve bu anlayışla dayatılan uzun çalışma süreleri de hekimlerin tıbbi hata yapma olasılığını artırmaktadır. Avrupa Birliği Mahkemesi kararlarında ${ }^{4}$ belirtilen hekimler için öngörülen azami çalışma sürelerinin -ki bu süre günlük 8 saat ve nöbet dâhil günlük 10 saat, her çalışma periyodu arasında kesintisiz 11 saat dinlenme süresi olarak bildirilmektedir- benimsenmesi ve sağlık hizmetinin özellikleri ile kamusal yarar düşüncesinden hareketle bu sürelerin uygulanması için gerekli düzenlemelerin yapılması, sağlık alanının acil intiyaçlarındandır.

Bu faktörlerin yanı sıra kusurlu eylemlere yol açabilecek diğer bazı faktörler de vardır. Bunların, diğer etkenlere göre uzun erimde daha tehlikeli sonuçları olacağını söylemek mümkündür. Her geçen gün tıp fakültelerinin sayısının ve bu fakültelere kabul edilen öğrenci kontenjanlarının artırılması, bu faktörlerden birisidir. Bugün tıp fakülteleri üzerinde bu tür kararlar alınırken, ne yazık ki tıp fakültesinin eğitici kadrolarının ve fiziksel olanakları ile donanımlarının yetersiz olduğu gerçeği göz ardı edilmektedir. Bu tür yetersiz koşullar, tıp eğitiminin niteliğini olumsuz etkilemektedir. Hekimlerin tutum ve beceri kazanmalarına yönelik olarak verilen tıp eğitimi gibi böylesi yaşamsal bir konuda yürütülen yanlış politikaların bir sonucu olarak, gelecekte tıbbi malpraktis sayılarında artış olacağını söylemek kehanet olmasa gerektir.

Yine, bilginin yarılanma ömrü ve aynı zamanda tıbbın hızlı değişen ve gelişen bir alan olduğu gerçeği de göz önünde bulundurularak hekimlerin mezuniyet sonrası tıp eğitimi üzerinde ciddiyetle durulması gerekirken, bu konuya gerekli önemin verilmemesi de sorunlara yol açabilecek bir başka neden olarak düşünülebilir. Ancak sistematik hale getirilmesi ve hekimlerin maddi ve manevi olarak desteklenmesi gereken sürekli tıp eğitimi alanında, bugün yeterli çalıșma yapılmamakta; hekimlerin kendi inisiyatiflerine bırakılan bu konudaki gereksinimi karşılamakta, meslek kuruIuşlarının ve uzmanlık derneklerinin gösterdiği takdire değer çaba ise geleceğe dair iyimser olmamızı sağlamaya yetmemektedir. Uygulanmakta olan performansa dayalı (hizmet karşılığı) ödeme yönteminin yarattığı tahribat ile seminer, vaka tartışması, literatür okumaları için ayrılması gereken zamandan vazgeçilerek hizmetin niceliğinin artırılmasına dönük bir çalışma modelinin gelişmesi de önümüzdeki dönemlerde tıbbi malpraktis vakalarının artmasında rol oynayacaktır.

Tıbbi malpraktis nedeniyle ortaya çıkan zararın en aza indirilmesinde, hekimleri hataya sevk eden koşullarının iyileștirilmesi büyük önem taşımaktadır. Ne var ki bugüne kadar tıbbi hataların önlenmesine yönelik tedbirlerin alınması yerine, bir süre tartışılan ve sonra gündemden kaldırılan "malpraktis yasası" ile uzun tartışmalara konu olan ve yasalaşan "zorunlu mesleki sorumluluk sigortası"nın sunulması, sorunu gidermekten son derece uzaktır. 
Bugün bir çözümmüş gibi ortaya koyulan tek şey olan sigorta sistemi, kişilerin zarar görmesini engellememekte; yalnızca uğradıkları zararın parasal olarak giderimi için bir ölçüde imkân yaratmaktadır. Maddi zararın karşılanmasına dönük olan bu sistemde hekimin cezai sorumluluğu ise tümüyle göz ardı edilmekte; hürriyeti bağlayıcı ya da mesleğini icra etmesine engel olabilecek cezalar alması ile ilgilenilmediği gibi, hastasını önemseyen her hekimin yaşadığı derin duygusal yıkımın ve mesleki motivasyon kaybının üzerinde de durulmamaktadır.

Özel sigorta şirketlerine büyük kaynak yaratan sigorta sisteminin, halen uygulanmakta olduğu Amerika Birleşik Devletleri örneğinde olduğu gibi ülkemizde de uzun vadede kamusal bir yarar sağlamayacağı ortadadır. Diğer ülke deneyimlerinin gösterdiği üzere; zaman içerisinde ödenecek sigorta primlerinin yükselmesi, buna karşın kişilerin zararlarının kısa sürede ve tam olarak giderilememesi, kusurun gizlenmesine yönelik davranış içine girilmesi gibi olumsuz sonuçları doğuran bu sistem, esas olarak kaynağa değil, sonuca odaklıdır.

Oysa tıbbi hata yaparak hastaya zarar verme konusunun, bir halk sağlığı sorunu olarak değerlendirilmesi ve sorunun çözümüne yönelik tedbirlerin alınması gerekmektedir. Bunun için tıbbi malpraktis olgularına dair verilerin toplanması ve özellikle sebep-sonuç ilişkisi üzerinden yapılacak analiz sonuçlarının rapor edilmesi iyi bir başlangıç olacaktır. Ancak zarara sebep olan temel nedenin saptanması ve kusurlu eylemin yeniden ortaya çıkmaması için gerekli önlemlerin alınması, konunun gerçek bir çözüme kavuşmasını sağlayabilir.

\section{SONUÇ}

Tıbbi müdahalelerde, ortaya çıkan sonuçtan bağımsız olarak kusura yol açan nedenler ve çözüm önerileri üzerinde daha çok düşünmeye gereksinim bulunduğu halde tıbbi malpraktis konusu, hekim ile hastanın karşı karşıya getirildiği hukuksal süreçler ve verilen nihai kararlar üzerinden ilgi odağı olmakta, bu konudaki tartışmalar da "hekimin cezai ve hukuki sorumluluğu" çerçevesine daraltılmaktadır. Ne var ki böyle bir bakış açısı ile sorunu çözmek ve kamusal yarar elde etmek olanaksızdır.

Sağlık hizmetinde hekim ve hastanın karşı karşıya getirildiği ve her türlü olumsuz sonucun hekime mal edildiği bir anlayışın terk edilmesi, çözüme yönelik ilk adım olmalıdır.

Bu alanda yapılacak düzenlemelerde, tıbbi uygulama hatalarının ortadan kaldırılması asıl amaç olarak belirlenmelidir. Bilinmelidir ki hekimlerin cezalandırıması, tıbbi hataların önlenmesinde öncelik verilecek bir tedbir değildir. Bu kapsamda meseleye bütüncül yaklaşılması, hata nedenlerinin araştırıması ve bu nedenlere yönelik önleyici çalışmaların sistemli bir biçimde düzenlenip uygulamaya geçirilmesi, çözüm için en temel unsurlardır.

\section{NOTLAR}

1. Yürürlüğe Koyan Bakanlar Kurulu Kararnamesi: No.4/12578 - 13 Ocak 1960

Resmi Gazete ile neşir ve ilânı: 19 Şubat 1960 - Sayı: 10436

2. 5237 sayılı Türk Ceza Kanunu -Resmi Gazete ile Neşir ve İlânı: 12 Ekim 2004 - Sayı: 25611, "Taksirle Öldarme"yi düzenleyen madde 85, "Taksirle Yaralama"yı düzenleyen madde 896098 sayılı Türk Borçlar Kanunu Resmi Gazete ile Neşir ve İlânı: 4 Şubat 2011 - Sayı: 27836 "Haksız Fiilden Doğan Borç İlişkisi”ni düzenleyen madde 49 vd. , "Vekalet Sözleşmesi"ni düzenleyen madde 502 vd.

3. 6023 sayılı Türk Tabipleri Birliği Kanunu ile kurulmuştur.

4. 09.09.2000 tarihli SIMAP kararı ve 09.09.2003 tarihli JAEGER kararı 